\title{
Sobre Cesare Pavese y sus Diálogos con Leucò
}

\author{
Carlos García Gual \\ Universidad Complutense de Madrid \\ cggual@filol.ucm.es
}

\begin{abstract}
Resumen
La obra Dialoghi con Leucò, considerada por el propio Pavese como su «carta de presentación para la posteridad»y, sin embargo, incomprendida y menospreciada por la crítica contemporánea, se convierte aquí en objeto de un estudio que destaca su validez significativa actual. El trabajo nos ofrece un interesante análisis sobre la concepción pavesiana del mito como elemento expresivo simbólico y autónomo que relaciona al escritor con las tendecias del idealismo alemán del siglo XVIII. La íntima relación entre mito y literatura nos ofrece el punto de partida para adentrarnos en el estudio de la obra en sí, tanto desde un punto de vista formal como temático e ideológico. La elección de una estructura dialógica permitió al escritor, pues, introducirse en una tradición mítica y literaria concreta, en la que se encuentra con el inevitable eco de la ironía melancólica de Leopardi. Asimismo, gracias a ella, Pavese puede acercarse al mito desde una perspectiva subjetiva y enormemente original.
\end{abstract}

Palabras clave: Dialoghi con Leucò, mito, símbolo, Leucótea, Pavese.

\section{On Cesare Pavese and his Dialoghi con Leucò}

\begin{abstract}
Dialoghi con Leucò, considered by Pavese himself as his «letter of introduction to posterity» and misunderstood and scorned by the critics of his time, will be the object here of a study that underscores its significance and validity today. First of all, the article gives us an interesting analysis of Pavese's conception of myth as a symbolic and autonomous expressive element, clearly linking the writer to tendencies in 18th-century German idealism. The intimate relationship between myth and literature offers us a point of departure for approaching the work from formal, as well as content-related and ideological, perspectives. The choice of a dialogic structure allows the writer both to enter a specific literary tradition that carries an inevitable echo of Leopardi's melancholic irony and to approach myth from a subjective and immensely original perspective. Finally, an analysis of the work's enigmatic title and a description of the myth of Leucothea are fundamental for interpreting a work that views myth as a vehicle for expressing the longings and emotions of both humanity in general and Pavese himself.
\end{abstract}


Key words: Dialoghi con Leucò, myth, symbol, Leucothea.

García Gual, Carlos. 2011. Sobre Cesare Pavese y sus Diálogos con Leucò. Cuadernos de Filología Italiana, $\mathrm{n}^{\mathrm{o}}$ extraordinario: págs. 177-186.

En 2008 habría cumplido sus cien años. Pero su cuenta se quebró a los cuarenta y dos, en 1950, al suicidarse en aquella habitación de un céntrico hotel en Turín. Ahora se le ha recordado -como hacemos en Madrid- en muchos lugares y en variados coloquios y reseñas, a la vez que se reeditan puntualmente muchos de sus libros, en español, francés, italiano, y otras lenguas, aprovechando la ocasión de este centenario. Las frecuentes conmemoraciones de estos aniversarios suelen siempre acarrear rituales elogios y nostalgias académicas impostadas, y despiertan discursos y glosas de retóricas más o menos académicas y oportunistas. No obstante, pueden servir de pretexto, o de invitación, para volver a leer y comentar desde nuestra circunstancia presente aquellos textos que nos atrajeron y conmovieron por su singular acento hace ya muchos años, y, de paso, meditar y reflexionar sobre su pervivencia actual, descubriendo matices nuevos en los bien conocidos textos. Algo que sucede habitualmente con los textos clásicos, pero también con otros que, por su propia textura poética, diría uno que conservan sugerencias múltiples. Hay textos que apenas envejecen, o que envejecen bien, como los vinos, y sostienen bien el paso del tiempo, o rejuvenecen a la luz de otra mirada.

En mi caso, y supongo que lo mismo les pasará a otros coetáneos, las lecturas de algunos libros de Pavese me suscitan la memoria de las de los primeros encuentros con sus textos, unos cuarenta años atrás. Prescindiré ahora, sin embargo, de todo intento de evocar con nostalgia aquellos años en que en un Madrid tardofranquista y soñoliento comentaba con compañeros de la Facultad lecturas de Pavese, mientras veíamos alguna película del cine italiano neorrealista, en la atmósfera brumosa de un existencialismo de provincias. ¡Qué atrás se ha quedado esa época que ahora veo alguna vez retratada con poco color, en sepia o en blanco y negro! Tampoco quisiera insistir en la evocación melancólica de la silueta personal de Pavese ni en su conocido contexto biográfico, sino que sólo pretendo, al socaire de las fechas, comentar la originalidad y el atractivo de una de sus obras: ese extraño libro titulado Diálogos con Leucò, que fue, según él escribió, su preferido, en contra de la opinión de la mayoría de los críticos contemporáneos. Justamente el libro que, de modo muy significativo, quedó en la mesilla de noche del hotel el día de su suicidio junto a la nota final de despedida: «Perdono a todos y a todos pido perdón. ¿Va bien? No hagáis demasiados chismorreos» (Pavese 1979: 467).

De antemano, debo decir que, de la amplia obra pavesiana, a mí siempre me atrajeron más sus poemas (e incluso los títulos de sus libros de poesía, como Trabajar cansa y Vendrá la muerte y tendrá tus ojos) que sus novelas (cuyos títulos son a veces no menos poéticos). Pero, sobre todo, debo alegar que, como a muchos de sus lectores, me impresionaron -por su sinceridad el uno, por su vigor poético el otro-, en la primera y en otras lecturas, sus diarios de los últimos años: El oficio de vivir, 
y Diálogos con Leucò ${ }^{1}$. (No sé si es necesario advertir que, como es notorio, no soy un crítico de la literatura italiana reciente ni siquiera un experto en el conjunto de la obra de Pavese; soy solo un lector fiel y añejo de sus obras. Pero, por otra parte, aprovecharé mi oficio de aficionado a los mitos antiguos y a las recreaciones y reflexiones sobre la mitología, para comentar, desde ese ángulo, sugerencias y rasgos propios de Diálogos con Leucò. De ahí el modesto enfoque y el breve alcance de estas líneas).

El título de Diálogos con Leucò se le ocurrió a Pavese cuando ya había avanzado en la redacción de esos «diálogos breves» (según una carta de 20 de febrero de 1946). De la breve serie de diálogos mitológicos el más antiguo, titulado Las brujas, lo escribió el 13 de diciembre de 1945, y el más tardío, Los hombres, el 31 de marzo de 1947. El mismo 20 de febrero redactó el prólogo (Avvertenza), un texto muy bien meditado y que conviene leer bien para entender su empeño. (Sorprendentemente, esas interesantísimas líneas no están en la versión española ya citada). Lo recuerdo íntegro ${ }^{2}$ :

De haber podido, habríamos prescindido de buen grado de tanta mitología. Pero estamos convencidos de que el mito es un lenguaje, un medio expresivo, es decir, no algo arbitrario, sino un vivero de símbolos al que pertenece, como a todos los lenguajes, una particular sustancia de significados que ningún otro podría expresar. Un prodigio mítico, decimos en media línea, en pocas sílabas, una cosa sintética y comprensiva, un meollo de realidad que vivifica y nutre todo un organismo de pasión, de estado humano, todo un conjunto conceptual. Y cuando recogemos un nombre propio, un gesto, un si luego este nombre, este gesto y prodigio, nos resulta familiar desde la infancia, desde la escuela, mejor que mejor. La inquietud es más auténtica y cortante cuando remueve una materia usual. Aquí nos hemos contentado con servirnos de mitos helénicos dada la perdonable boga popular de esos mitos, su inmediata y tradicional aceptabilidad. Nos horroriza todo lo que es descompuesto, heteróclito, accidental, y pretendemos -inclusive materialmentelimitarnos, darnos un marco, insistir sobre una presencia conclusa. Estamos convencidos de que una gran revelación sólo puede salir de la testaruda insistencia sobre una misma dificultad. No tenemos nada en común con los viajeros, los experimentadores, los aventureros. Sabemos que el más seguro - y el más rápidomodo de asombrarnos, es mirar impertérritos siempre el mismo objeto. En determinado momento nos parecerá - milagroso- que nunca lo habíamos visto ${ }^{3}$.

${ }^{1}$ Apunto que leí El oficio de vivir en la traducción española de Luis Justo (Pavese, 1965). Dialoghi con Leucò lo conocí primero en la edición italiana de Mondadori (1966); luego lo he releído en la traducción de Esther Benítez (Pavese 1980). Los artículos de Pavese sobre el mito los cito por la benemérita versión española de La literatura norteamericana y otros ensayos de Bruguera (Pavese 1987: 305-364).

${ }^{2}$ Este «prefacio a los dialoguillos» sí está incluido en El oficio de vivir (Pavese 1965: 275-6). Está también en la versión de El oficio de vivir hecha por E. Benítez (Pavese 1979: 400-401). Cito por esta.

${ }^{3}$ La importancia de estas líneas introductorias se ha subrayado muchas veces. Citaré, como ejemplo, «Per gli altri, i dubbiosi o i detrattori, ha già messo le mani avanti nella premessa al libro.[...] Potendo si sarebbe fatto volentieri a meno di tanta mitologia. Ma siamo convinti che il mito è un linguaggio, un mezzo espressivo - cioè non qualcosa di arbitrario ma un vivaio di simboli cui appartiene, como a tutti i linguaggi, 
Estas líneas ilustran muy bien la actitud de Pavese al recurrir a esa mitología. Que en el mito se vea un lenguaje sui generis, un instrumento singular para expresar simbólicamente una realidad, o una percepción colectiva -y a la vez de uso muy personal- de una realidad que no puede presentarse de otro modo, es decir, que está más allá de los moldes expresivos de la lógica, no es una idea original. Ya los pensadores y poetas alemanes del XVIII habían abundado en esa autonomía expresiva del mito como un código propio con su propia poética y su trascendencia en el ámbito imaginario, y, desde luego, por sus lecturas Pavese conocía muy bien todas esas teorías simbolistas.

Furio Jesi, temprano y perspicaz comentarista de esos textos, lo había detectado muy bien, notando cómo la visión pavesiana enlaza con ese idealismo simbolista, y se aparta tanto de la interpretación funcionalista de Malinowski como de la anterior teoría ilustrada, evolucionista, de Sir James Frazer:

Es significativo que Pavese, por lo que respecta al valor simbólico del mito, rechace la teoría de un sentido «empírico», como decía Malinowski, para aceptar más bien, -aunque no de un modo ortodoxo- la de Kerényi, es decir, la que parece derivar no de una indagación puramente etnológica, sino de las especulaciones sobre el símbolo con acentos diversos en el ambiente de la poesía germánica, pero más en conexión con la teoría de Goethe que con la de los románticos ${ }^{4}$.

Con su pregnancia imaginativa, el mito servía para calmar mejor esa inquietud inextinguible a la que hace alusión; el mito tiene una contenida riqueza y alude a realidades que no alcanza la lógica habitual. Como Pavese dice en otro lugar ${ }^{5}$ : «Un mito es siempre simbólico, por esto no tiene nunca un significado unívoco, alegórico, sino que vive de una vida encapsulada que, según el lugar y el humor que lo rodea, puede estallar en las más diversas y múltiples florescencias».

Pavese conocía varías mitologías, no solo antiguas, sino también de tierras lejanas, como lector y editor de libros de antropología en la editorial Einaudi, y por esos resulta mucho más interesante su declaración y su reflexión de que solo la de los antiguos griegos, la más conocida por los europeos, ofrecía una respuesta familiar a sus punzantes cuestiones. En principio, porque sus mitos estaban ligados a una educación, y también porque la riqueza de esa mitología, transmitida por una larga lite-

una particolare sostanza di significati che null'altro potrebbe rendere. Insiste comunque a difenderlo, contro gli imbarazzati silenzi e le incomprensioni; adottando perfino una punta di alterigia e di sprezzo. Sembra impossibile che Leucò non si capisca ma ciò mi riempie di gioia. Vuol dire che è proprio come il secondo Faust. Certo i Dialoghi, così risonanti rispetto al Compagno, sono la sua creatura più cara, come dimostrano anche le riflessioni e gli arzigogoli che li acompagnano nel diario lungo tutto il ' 47 [...] Non diversamente da quello che sentono i pur affascinati lettori» (Muñiz Muñiz 1992: 167).

${ }^{4}$ V. (Jesi 1972: 146). Es curioso que Pavese prefiriera adherirse a esa interpretación simbolista, vinculada a la época del idealismo alemán, y no a las teorías de autores funcionalistas que él había editado en la serie de estudios sobre mitología que dirigía en la editorial Einaudi. Como si su sensibilidad como poeta se impusiera a la del novelista y editor atento a las corrientes más modernas, más pragmáticas.

${ }^{5}$ V. (Pavese 1987: 305-64, 308-9). He citado esa frase mi libro (García Gual 2007), donde resumo diversas interpretaciones modernas de la mitología, desde los simbolistas románticos a Frazer, a Lévi-Strauss. 
ratura, recreada poéticamente a lo largo de siglos, resulta incomparable, y revela una curiosa y singular "madurez mítica", ligada a su tradición en un marco histórico y espiritual de extenso horizonte. Insiste en ello:

La fascinación de los mitos griegos nace del hecho de que posiciones inicialmente mágicas, totémicas, matriarcales, fueron -por la elaboración ágil del pensamiento consciente sobrevenida en los siglos X-VIII a. C.- objeto de nuevas y profundas interpretaciones, de contaminaciones, de injertos, -todo ello presidido por la razón- y de este modo llegaron a nosotros con la riqueza de toda esa claridad y tensión espiritual, aunque también abigarradas de antiguos sentidos simbólicos ajenos (Pavese 1979: 304).

Los mitos conservan una fuerza poética propia, singular, que puede ser invocada o resucitada por un buen intérprete. De ahí su potencial literario; y también su alcance especulativo.

Debes guardarte -sigue diciendo- de confundir el mito con las redacciones poéticas que de él se han hecho o se están haciendo; precede a la expresión que se le da; no es esa expresión; en su caso se puede hablar perfectamente de un contenido distinto a la forma (aunque de una forma por sumaria que sea no se puede prescindir jamás); y esto lo prueba el hecho de que el verdadero mito no cambia de valor, ya se exprese en palabras, con signos, o con música. El mito es, en suma, una norma de un hecho ocurrido de una vez por todas, y extrae su valor de esa unicidad absoluta que lo alza por encima del tiempo y lo consagra como revelación. Por eso se produce siempre en los orígenes, como en la infancia. Está fuera del tiempo (Pavese 1979: 305).

No vamos a detenernos ahora en comentar el trasfondo de estas ideas. Sería fácil conectarlas con textos de Karl Kerényi, C.G. Jung, Joseph Campbell o Mircea Eliade, por ejemplo. Más interesante ahora es subrayar esa conciencia de que los mitos en toda cultura $-\mathrm{y}$ muy claramente en nuestra cultura occidental- circulan a lo largo de la tradición como una herencia colectiva, están arraigados en un imaginario que, aun desligado de su función religiosa, se trasmite en la literatura y en el arte, desde los griegos. La tradición reelabora esos mitos en variados formatos y los usa para reflexiones y recreaciones varias. Es lo que Hans Blumenberg ha denominado «trabajo sobre el mito». En su espléndido libro Arbeit zum Mythos H. Blumenberg insistió en la «significatividad» que, en un principio, los mitos aportan a la interpretación humana del mundo.

Desde luego, Pavese no pudo conocer ese libro (Blumenberg 1979), pero habría estado muy de acuerdo con sus tesis sobre la "constancia icónica» de esos relatos que son una y otra vez recontados y reinterpretados. Y que, de modo ingenuo o irónico, vienen a calmar esa inquietud ante la realidad cósmica inventando un trasfondo de figuras fantasmales. Pavese, no solo poeta y novelista, sino ensayista y editor, un intelectual comprometido, conocía varias mitologías, pero era muy consciente de que solo la de los griegos, al menos para los europeos, ofrecía una respuesta familiar a sus punzantes cuestiones. 
Como ya se ha dicho, los mitos pueden presentarse en formas literarias diversas, y eso sucede ya en la antigua literatura helénica. Tanto la épica como la lírica y la tragedia griegas relatan cada una a su manera los mitos del repertorio tradicional. Y el diálogo puede también servir para ese fin, aunque no sea una de las maneras más usuales y espontáneas para contar ingenuamente los mitos. Elegir ese formato de los diálogos breves -que no apuntan a la mera narración, sino que colorean dramática o irónicamente el texto, con un toque de subjetividad al poner la narración en boca de determinados caracteres-, es seguir un cierto modelo literario. En la tradición griega el de los diálogos de Luciano; en la italiana, los de Leopardi ${ }^{6}$. (En contraste con los opúsculos del satírico de Samósata, en los de Pavese, que no pretende caricaturizar a los dioses y héroes, no hay tono burlón ni rasgos cómicos, pero sí una inevitable ironía poética, de tintes melancólicos. En esa línea está, desde luego, próximo a Leopardi. La elección de ese formato, de forma muy consciente, subraya esa intención irónica) ${ }^{7}$.

Como se espera, la forma del diálogo breve tiende a rememorar los mitos desde miradas subjetivas. No se trata de resumir los relatos míticos, sino de aludir a ellos y rastrear en ellos sus rasgos inquietantes o notas enigmáticas. Es muy significativo de su idea el hecho de que Pavese anteponga a cada texto unas líneas que resumen de manera previa la escena y cuentan quiénes son los actores del breve encuentro, para situar al lector, que podría desconocer o no recordar ese contexto, por más que los mitos sean conocidos. Digamos que, aunque los personajes sean conocidos, no suelen ser de los más habituales en los tablados de la mitología. Al sesgo de su evocación de los textos clásicos, los encuentros y diálogos abren una perspectiva propia, insinuando aspectos y cuestiones que nos hacen reflexionar sobre la condición infeliz de hombres y dioses, con un toque existencialista y subversivo, de acentos ácidos e irónicos, ecos de su propia inquietud.

Como señala Lorenzo Mondo, bajo la superficie mitológica se desliza una inagotable inquietud.

El sentido último de estos Diálogos parece resolverse en una contrastada inquietud religiosa, en una anámnesis torturante y recurrente. Conviene de todos modos

\footnotetext{
${ }^{6}$ Lo señala ya Nieves Muñiz, (1992: 111-3): «Rialacciandosi dunque a questa tradiziones (dietro cui stavano anche Platone e Luciano), Pavese capovolse l'operazione compiuta in La terra e la morte per mostrare il rovescio della medaglia: non più (o non soltanto) dramma umano proiettato nel mito, ma il mito stesso visto nel duplice senso cui ho acennato prima, come proiezione del dramma umano.» [...] «Riportando al presente la mitologia antica egli tentava dunque un'operazione di estraneazione volta a impedire che - a causa della eccessiva familiarità dei lettori con la versione vulgata - se ne disperdesse la pregnanza, ma poi utilizzava quella stessa familiarità del pubblico con le letture scolastiche come un' arma indispensabile per dare alla propria opera la profondità e la credibilità dei ricordi infantili, il solo vero mito dell'uomo moderno». Son excelentes también sus observaciones sobre la dificultad y el atractivo (Muñiz 1992: 129).

7 «Para quien sabe escribir, una forma es siempre algo irresistible. Corre el riesgo de decir tonterías y de decirlas mal, pero la forma que lo tienta, pronta a embeberse en sus palabras, es irresistible. (Me refiero, por ejemplo, al género del pequeño diálogo mitológico tuyo» (27 septiembre 1946; Pavese 1987: 209). La originalidad en la preferencia por ese formato, a la vez que la referencia a los diálogos de Leopardi, la señala ya Muñiz (Muñiz, 1992: 98).
} 
subrayar su complejidad, su carácter irreductible a una lectura unívoca. Es un libro de fugas y retornos, de ocultamientos y de emergencias. Presenta una arquitectura ambiciosa que a cada paso se desmonta, se abre a representaciones y argumentaciones divergentes, en un continuum que refleja el fluir de una conciencia indecisa (Mondo 2006: 152).

Los Diálogos son un texto de difícil lectura, de un oscuro simbolismo, que puede desconcertar a más de un lector, como de hecho sucedió en su tiempo ${ }^{8}$; un texto que pareció extravagante e inconfortable a los críticos y a los filólogos, con la honrosa excepción del clasicista Mario Untersteiner, uno de los grandes estudiosos del pensamiento griego y un intelectual de singular sensibilidad e inteligencia, que desde muy pronto comprendió todo el alcance poético y la originalidad de la obra. El desconcierto que produjo el libro en la crítica contemporánea lastimó, sin duda, a Pavese, que había puesto en esos Diálogos mucho de su sentir y pensar más íntimo. Pero él quiso asumir esa decepción con un cierto orgullo, y con irónica alegría9.

¿Por qué el título de Diálogos con Leucò? En principio, podríamos ver en él una alusión al nombre de su amada de esos años: Blanca Garufi. Pero, además, Leucò es diminutivo de Leucótea, «la Diosa blanca», una figura mítica de discreto relieve en el repertorio antiguo, divinidad menor, pintoresca y marina, muy al margen de los grandes dioses del Olimpo ${ }^{10}$. Ino Leucótea tiene solo una aparición relevante en la literatura griega. Aparece en la Odisea, canto V, versos 333 y siguientes, para auxiliar a Ulises, zarandeado en su balsa por una furiosa tempestad enviada por su enemigo Poseidón. Surge del mar como una gaviota y le habla y le da un velo mágico con el cual el héroe debe arrojarse al borrascoso mar, y sobrevivir hasta llegar náufrago a Feacia. En los veintisiete diálogos del libro de Pavese, solo aparece en dos: el primero, el de Las brujas (donde charla con Circe y se evoca el episodio del encuentro de Ulises con la maga que trans-

\footnotetext{
${ }^{8}$ Cf. (Muñiz 1992: 130). También Lorenzo Mondo (2006: 149-53) comenta el rechazo casi unánime a la obra de la crítica literaria contemporánea, que no sabía dónde situarla. Con todo, me parece dudosa su observación sobre la influencia de Nietzsche sobre este texto. Pavese había leído El origen de la tragedia en 1940, es decir algunos años antes de pensar en estos «dialoguillos míticos», que distan mucho del fervor dionisíaco, tanto por su estilo como por su contenido.

${ }^{9}$ De nuevo cito unas líneas de Nieves Muñiz (1992: 129): «Una vera e propria somma della problematica e della poetica di Pavese. Si capisce così che l'autore sostenesse fino all'ultimo l'importanza di questo libro poco gradito a critici e lettori e lo definisce come il suo «biglietto di visita presso i posteri» (cf. la lettera a Billi Fantini datata 20 luglio 1950) [...] «L'ostacolo maggiore per la fortuna dell'opera fu senza dubbio l'ambiguità del suo stile, che, situandosi a metà strada fra simbolo e allegoria, è nel contempo aforisticooracolare (di cui il ricorso a parole-mito aparentemente semplici - "destino", "ricordo", "isola", "strade", "rupe", "belva"- ma cariche d'implicazioni inedite) e schiettamente argomentativo (saranno gli interlocutori stessi a construire e chiarire i significati dei termini nel corso del dibattito). Dunque, mito di dipanare (ed ecco gioire delle difficoltà incontrate dai lettori: "Sembra impossibile che Leucò non si capisca, ma ciò mi riempie di gioia", 26 nov. 1948 ), e dipanamento di miti».

${ }_{10}$ Apunto, de pasada, que solo coincide en el nombre con la poderosa Diosa blanca patrocinada por Robert Graves, en un libro que con ese mismo nombre (The White Godess) se publicó algunos años después.
} 
forma a sus huéspedes en cerdos y lobos), y, más adelante, el de La viña (donde anuncia a Ariadna, abandonada por Teseo, la pronta llegada de Dioniso). La diosa es una confidente marginal de los amoríos de Circe y Ariadna, amantes de héroes aventureros y seductores. Junto a Las brujas hay en el libro solo otro encuentro inspirado en la Odisea: La isla, donde dialogan Calipso y Odiseo. (Nuevo tema del abandono y el amor insatisfecho).

De todos modos, recordemos que, siendo el primero de los diálogos, Las brujas, marcó el camino a seguir; fue algo así como un ejemplo para los demás encuentros. Ya en ese texto está el motivo recurrente en tantos otros: la inmortalidad divina se enfrenta a la existencia mortal, y una y otra condición se revelan como insatisfactorias. Los héroes siguen su camino, mientras que las bellas inmortales, tanto Circe como Calipso, se quedan en sus islas abandonadas. Dejándolas atrás los astutos héroes se apresuran hacia un destino que acaba en muerte. Pero la inmortalidad no es tampoco garantía de felicidad. Los héroes pasan, sin que el amor los retenga, y las diosas se quedan solas con el recuerdo de una relación fugaz. No sé si Pavese pensaría también en el extraño destino de Leucótea: una mortal que, en su desesperación, se suicida arrojándose al mar, pero a la que los dioses le conceden, raro privilegio, la condición de diosa en las profundidades marinas. De allí emerge para auxiliar a Ulises. Pavese sentía pasión por la Odisea homérica, y tuvo un tenaz interés en buscarle una nueva versión italiana. Me parece evidente que en esas imágenes de la parlera Leucótea late el recuerdo del pasaje homérico, aunque la gaviota y el velo ahí no se mencionen.

Pavese recurre a los mitos griegos -0 , mejor dicho, a figuras y coloquios fingidos entre los personajes del imaginario mítico- para dar expresión a sus propias inquietudes y desasosiegos, como si en esas imágenes y en sus destinos trágicos hallara un medio para expresar de modo enigmático anhelos sin respuesta. Bajo las máscaras de héroes y dioses nos invita a asistir, a través de ese intercambio de reflexiones y recelos ${ }^{11}$, a unos coloquios en un mundo de sombras. Como un pasaporte para ese fantástico teatro de sombras, como un velo de Leucótea para sobrenadar en la tormenta, extrae del viejo repertorio helénico esas figuras míticas, un tanto desconcertantes. No le interesa referir las hazañas prodigiosas de los dioses y los héroes, no evoca con retórica escolar el fulgor de esas fantasías, sino que comenta, a través de esas charlas, despedidas, fracasos, desilusiones, amores sin rumbo, quiebras de la felicidad. Ni la condición divina ni la arrogancia heroica son satisfactorias, y se anhelan en vano una a otra. ${ }^{12} \mathrm{El}$ destino resulta absurdo e inevitable, y las preguntas se estrellan contra un muro. La selección de personajes y de episodios con

11 Los mitos se prestan a esas interpretaciones -que unas veces son más irónicas o burlescas, como en los Diálogos de los dioses de Luciano- y otras más melancólicas. Hay en esos relatos un elemento dramático que se presta a ser coloreado con variable tono sentimental, hay en los mitos una cierta ambigüedad o ambivalencia, como señala Muñiz (1992: 98): «Questa ambivalenza del mito - verità e menzogna, ferita e terapia - si proiettava sul concetto pavesiano di catarsi artistica, la cui aspirazione a far parlare il mito di se stesso comportava l'impossibilità di uscire del suo circolo ermeneutico [...] Da questo groviglio e da questa ambiguità nasceranno i Dialoghi con Leucò, certamente, l'opera più ambiziosa di Pavese, ma tutt'altro che un' opera isolata». 
final amargo es muy característica. Podríamos recordar, aplicada al juego con los mitos, la frase de Derek Walcott: «Los clásicos consuelan, pero no bastante». Solo queda un furtivo placer, o un ambiguo consuelo, en las palabras, en los razonamientos sobre el pasado y el destino, en el juego con las imágenes de esas figuras fantasmagóricas, marionetas ilustradas del teatrillo de la memoria, marginales al Olimpo de los Felices.

Leucò - en la Odisea - emerge del fondo marino como parlera y blanca gaviota. (Las diosas antiguas gustan de esas metamorfosis en veloces aves). Le aconseja a Ulises abandonar su almadía, y, tan sólo abrigado con su velo, echarse a nadar en el mar embravecido. Ulises, un tanto desconfiado siempre ante las ayudas divinas, obedece al rato, y así llega dos días después más tarde a la isla de los feacios. Apenas arriba a la costa, desnudo y náufrago, arroja el héroe de nuevo el velo al mar, como le dijera la diosa marina, y prosigue su complicado regreso. Resulta un estupendo símbolo ese misterioso y mágico velo: un salvavidas prestado por la furtiva diosa metamorfoseada en parlera gaviota - una diosa que antes había sido una mujer de existencia trágica.

Podría decirse que los mitos pueden usarse, como el velo mágico de Leucò, a modo de salvavidas ocasional para náufragos en apuros. En esos breves coloquios puede darse cabida a las emociones y anhelos de nuestra propia condición humana, tan humanas son las figuras de ese repertorio fabuloso. Pero solo por un tiempo; es inevitable tener que devolver el velo más o menos pronto al mar, y enfrentarse de nuevo a la inquietud cotidiana. Para la mayoría de sus lectores de entonces, como ya hemos subrayado, Diálogos con Leucò resultó una obra muy extraña, una extravagancia difícil de aceptar en la trayectoria del novelista y poeta comprometido con la ética y estética del realismo contemporáneo. Podemos explicarnos el rechazo general de la crítica, desconcertada y escandalizada, un rechazo casi unánime. Ante ella Pavese, como ya hemos dicho, se sintió dolido, sorprendido hasta cierto punto ante su incomprensión; aunque luego se jactara, como hemos notado, de cierta alegría ante ese rechazo. Para él era la obra que mejor lo definía, en su complejidad, su inquietud poética y existencial, y por eso escribió -en carta a una amiga y poco antes de su suicidio- que la consideraba su "carta de presentación ante la posteridad" (biglietto di visita presso i posteri). No fue así para la gran mayoría de su público lector.

${ }^{12}$ Aquí quiero citar unos párrafos muy sugerentes de L. Mondo: «Gli dèi possono nutrire una sovrana indiferenza per la sorte degli uomini (Giacinto ucciso dal luminoso Apollo solo "per esprimere un fiore") che non esclude una strana invidia, como se sentissero il bisogno di loro. Nelle creature che affrontano un destino di morte, "arricchendo la terra di parole e di fatti", come Odisseo, si consuma paradossalmente una esperienza di libertà negata agli inmortali: Circe arriva a dire che, per uscire dal tedio del sempre uguale, occorrerebbe farsi mortali. Eppure qui sarebbe il nuovo, che spezzerebbe la catena [...] Il senso ultimo di questi Dialoghi sembra risolversi in una contrastante inquietudine religiosa, in una anamnesi torturante e rimossa. Occorre tuttavia ribadire la loro complessità, la loro irriducibilità a una lettura univoca. È un libro di fughe e ritorni, di nascondimenti e riaffioramenti. Presenta una archittetura ambiziosa che ad ogni passo si sfalda, si apre a rappresentazioni e argomentazoni divergenti, in un continuum che riflette il fluire di una coscienza indecisa» (Mondo 2006: 151-152). 
Debemos, pues, apreciar ese gesto suyo cuando quiso dejar, no por azar, sino con plena consciencia de su sentido, el libro de los coloquios míticos, como un testimonio de sus inquietudes sin respuesta, como una nostalgia hacia el paisaje antiguo, como un paseo entre sombras y fantasmas de otros tiempos, entremezclados los ecos de la infancia y las siluetas de diosas y héroes, con su extrañeza y su cálida y ambigua familiaridad, voces antiguas resonando para expresar angustias y dudas de siempre.

Releer los Diálogos con Leucò, un texto tan ambicioso y mucho menos leído de lo que merece, y a la vez recordar cuánto significaron estos breves dramas para su autor puede ser, aquí y ahora, un buen esfuerzo intelectual a la vez que un cordial y amistoso homenaje al gran escritor. Considero, por otra parte, que es uno de los textos más interesantes de un humanista del siglo XX, uno de los raros "clásicos" europeos del siglo, un magnífico ejemplo de la inagotable capacidad de sugerencias que -más allá de cualquier retórica y de la acartonada erudición clasicista- guardan todavía los antiguos mitos griegos.

\section{Bibliografía}

BLumenBerg, Hans (2003): Trabajo sobre el mito (1979), trad. de P. Madrigal. Barcelona, Paidós.

GARCía GuAL, Carlos (2007): Introducción a la mitología griega. Madrid, Alianza. JESI, Furio (1972): Literatura y mito. Barcelona, Seix Barral.

Mondo, Lorenzo (2006): Quell'antico ragazzo. Vita di Cesare Pavese. Milano, Rizzoli. MuÑIz MuÑIZ, $\mathrm{M}^{\mathrm{a}}$ de las Nieves (1992): Introduzione a Pavese. Bari, Laterza. PAVESE, Cesare (1965): El oficio de vivir, trad. de L. Justo. Buenos Aires, Siglo XXI. PAVESE, Cesare (1979): El oficio de vivir, trad. de E. Benítez. Madrid, Bruguera Alfaguara. PAVESE, Cesare (1980): Diálogos con Leucò, trad. de E. Benítez. Madrid, Bruguera. PAVESE, Cesare (1987): La literatura norteamericana y otros ensayos, trad. de E. di Fiore. Madrid, Bruguera. 